\title{
THE INFLUENCE OF HOSPITAL SERVICE CREDIBILITY ON PATIENTS' REVISIT INTENTION
}

\author{
Chai Yin Sia \\ Faculty of Business, Multimedia University, Jalan Ayer Keroh Lama, Melaka, Malaysia \\ chaiyin9521@yahoo.com \\ Kim Piew Lai* \\ Faculty of Business, Multimedia University, Jalan Ayer Keroh Lama, Melaka, Malaysia \\ kplai@mmu.edu.my \\ Mohd Nazri Mohd Noor \\ Faculty of Business, Multimedia University, Jalan Ayer Keroh Lama, Melaka, Malaysia \\ nazri.mohdnoor@mmu.edu.my \\ Hishamuddin Bin Ismail \\ Faculty of Business, Multimedia University, Jalan Ayer Keroh Lama, Melaka, Malaysia \\ hisham@mmu.edu.my \\ David Yoon Kin Tong \\ Faculty of Business, Multimedia University, Jalan Ayer Keroh Lama, Melaka, Malaysia \\ yktong@mmu.edu.my \\ Yee Yen Yuen \\ Faculty of Business, Multimedia University, Jalan Ayer Keroh Lama, Melaka, Malaysia \\ yyyuen@mmu.edu.my \\ * corresponding author
}

\begin{abstract}
This conceptual paper aims at developing a research framework which explains how service credibility influences patients' revisit intention. Service credibility relates to the trustworthiness and the expertise of an organization that delivers on its promises to consumers. However, the context of service credibility remains understudied especially in a hospital setting. The relationship marketing theory will be applied in this study. Besides providing insights on how service credibility influences patients' revisit intention, the decision convenience and affective commitment of patients and their influences on revisit intention will also be investigated. The decision convenience and affective commitment can be considered as the mediators that mediate the relationship between the service credibility and patients' revisit intention. This study provides several implications for marketers and suggestions for future research.
\end{abstract}

Keywords: service credibility, revisit intention, decision convenience, affective commitment, hospital

\subsection{Introduction}

Ministry of Health, Malaysia $(\mathrm{MoH})$ indicated that healthcare industry is the highest and the fastest-growing industry from the year 2000 to 2009 and therefore has become an important driver for Malaysia's economic growth. Accordingly, healthcare industry's stakeholders - including public and private hospitals - have committed to the process of developing the country to become a leading destination for medical tourism (Koris, 2017). In the year 2016, healthcare industry contributes to Malaysia's GDP exceeding RM1billion (US\$226million) and is expected to increase by 33\% in the year 2017 (Macleod, 2017).

The economic advances have given hospitals opportunity to grow and provide beyond the ordinary service, most especially, reliable healthcare service in an accessible and effective manner. However, the characteristic of a service is often intangible and has a high level of the uncertainty, consumers would, therefore, unable to evaluate the service effectively before making purchase decision (Berry, 2000). In this sense, evaluating a healthcare service before decision making has become a challenge. With these diverse issues in providing healthcare service, recent attention has focused on the service credibility that evokes the preferences of patients (Wang \& Yang, 2010). Service credibility can build good individual impressions 
and aspire to create a competitive advantage. Service credibility, in a hospital setting, evokes differential reactions and influences the perception of patients regarding the efforts of healthcare providers (Jeng, 2016).

Service credibility represents also the warranty of a service and for this, it can be regarded a "value" for the hospital. When patients think about the hospital, they will consider a hospital that offers a good service and trustworthy. The credibility of a service is an important key that reduce patients' sense of uncertainty. The understanding of how the service that acts a role to influence patients' decision has been and associates with a primary care to a long-established area of interest among marketers (Wang \& Yang, 2010). Service credibility is important because it represents the quality of a healthcare service. For patients, a credible service can assure their health concerns and safety issues. To reduce patients' sense of uncertainty, they need to have the trust in the performance of the hospital. For the management, a credible service can indicate that their marketing efforts has become more cost-effective. This is because of the high likelihood of message acceptance from the general public (Jeng, 2016).

Service credibility serves as an important driver to influencing consumers behaviour and their decision making (Erdem, 2014). In this study, the consumer who purchases the service is the patient in the hospital. Patients have their preference for the service when they do the selection process. When patients trust the service, they will engage and continue with the healthcare service. A good service credibility can help a business to stand out from competitions and to have higher revenue.

This research can contribute to existing literature in several ways. First, this research examines the effects of service credibility in a hospital setting, by applying relationship marketing theory for future discussion, thus can provide improvements to the theoretical knowledge. Second, this study investigates the roles of decision convenience and affective commitment as the important mediators in the relationship between service credibility and patients' revisit intention. This is in view that decision making for the health-related issues, i.e. treatment, healthcare, would be difficult for patients (Berry, Seiders, \& Grewal, 2002). This study forsees that service credibility might improve patients' decision convenience and affective commitment. This is because the credibility of the service can provide clear and accessible information to patients.

Third, this study extends the discussion about service credibility as a signal to patients (Jeng, 2016). The relationship marketing theory is relevant because it explains the effects of service credibility and how credible service can influence the patients' decision through the psychological and social influence processes.

\subsection{Literature Review}

\subsection{Relationship marketing theory}

Relationship marketing refers to the application of the communication created by sellers to develop permanent and long-term relationships with customers (Solayappan \& Jayakrishnan, 2010). In the healthcare industry, relationship marketing relates to the application of the communication made between an organisation and patients to better understand the healthcare professions and to develop a long-term relationship.

Relationship marketing becomes apparent when an organisation integrates its efforts to maintain, identify and establish a relationship with targeted consumers and to enhance the strength of communication network (Morgan \& Hunt, 2012). A similar study of Palmatier, Dant, and Grewal (2007) shows that an established relationship can cause a direct effect on sales performance, and this effect can also be affected by the consumers' commitment, relational norms and consumers' trust. In this sense, relationship marketing theory is about the trust of consumers and the affective commitment of consumers. It suggests that the credibility of the service will build the relationship between the consumers and an organisation. In this study, affective commitment is the important perception representing the attribute of the relationship and can be referred as the psychological attachments of loyalty and the affiliation to the relationship partners (Bolton, Lemon, \& Verhoef, 2004). Consumers will feel comfortable and joyous when using a credible service, leading to a good impression of the service. The relationship marketing can create a customer connection and let the customer trusts the credibility of the service. The basic concept of the relationship marketing is that consumers engage a loyalty relationship with the marketer to reduce choices (Bolton, Lemon, \& Verhoef, 2004). Consumers need to have a decision convenience so they have the tendency to save their time and money from learning new service experience. Loyal customers commit to repurchase or continue with a service when the relationship with the marketer is strengthened and they trust the performance of the service.

\subsection{Revisit Intention}

Revisit intention is the status of consumers' desire to continually purchase the same service in future (Chung \& Lee, 2003). Consumers will select the same service provider and buy the same service based on their past experience as a reference to a good quality service. The performance of the service in the consumers' last purchasing experience will be an important factor to motivate their revisit decision (Sehgal, 2014). The Submit Date: 10.07.2018, Acceptance Date: 22.08.2018, DOI NO: 10.7456/1080SSE/176

Research Article - This article was checked by Turnitin

Copyright (C) The Turkish Online Journal of Design, Art and Communication 
reason consumers choose the same service is related to the premise of their past encounters. The revisit intention of a customer can signify that the consumers trust the service and they have perceived the service as having a good quality.

\subsection{Service Credibility}

Credibility is the perceived quality of being believed or accepted as true, real or honest to a certain service (Ahmed, 2015). There are two main components of the credibility, i.e. trustworthiness and expertise. Trustworthiness is the consumers' believability on a certain service and that the service will fulfil its promises and the expertise capability of the service (Erdem, 2014). Both trustworthiness and expertise will reflect the confidence of the consumers in the service. In this sense, credibility can be regarded as the most important driver for performing an alternative or be a signal to influence the customers' decision (Seyed Ghorban \& Tahernejad, 2012). Consumers who have high trustworthiness in a service, will trust the service and will develop a positive perception towards the organisation and other service lines. Credibility of a service can be considered as a favourable behaviour and indicated that the same service has better chance to be repurchased for future use.

\subsection{Decision Convenience}

Decision convenience is the consumers' time and effort involved in a decision-making process, in using a service and in choosing similar service from other organisations (Farquhar \& Rowley, 2009). Decision convenience suggested that the consumers who desire a particular performance will devote his time and effort to decide the alternative that fulfils his need or want (Berry et al., 2002). In this study. the decision convenience is the time taken and how easily a consumer can decide or to make a favourable buying decision at a premise (Sehgal, 2014). With this notion, decision convenience can be defined as the consumers' perceived degree of reducing time spent and thinking effort when making a decision. When the consumers have the decision convenience, they will revisit or repurchase to fulfil their need or wants.

\subsection{Affective Commitment}

Affective commitment is the involvement, identification and emotional attachment of the consumers to an organization (Iglesias, Singh \& Batista-Foguet, 2011). Affective commitment will create a "stickiness" which makes consumers be loyal to the service or organisation (Crisnayanti, 2015), in which based on their previous experience. Affective commitment can also represent the psychological state of the consumers that reflects the affective nature of their relationship related to the service providers (Gundlach, Achrol, \& Mentzer, 1995). Consumers seek positive affective responses from purchasing a service and remember their previous experience as their service knowledge. The affective commitment is an indication of the consumers' feeling towards a service (Kemp \& Bui, 2011). This will lead the consumers to repurchase the goods or service when they have a good experience even before their first contact with the providers.

\subsection{Research Framework}

Figure 1 shows the research framework that will be applied in this study. This research framework is adapted from Jeng (2016). Service Credibility, Decision Convenience and Affective Commitment are the independent variables and Revisit Intention is the dependent variable. The study proposes five hypotheses based on the relationships between the independent variables and dependent variable as above.

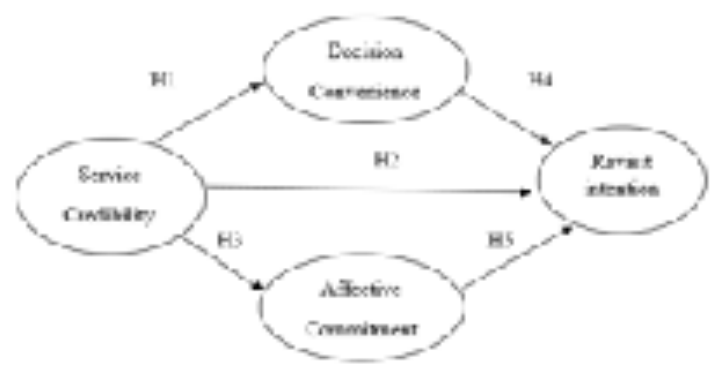

Figure 1: Research Framework

\subsection{Relationship between service credibility and decision convenience}

A good service credibility can be a signal to help the patients as consumers for making a better healthcare decision. Normally, when patients face high uncertainty they tend to purchase credible healthcare services (Erdem, 2014). Patients will perceive the healthcare service to be risky when they feel uneasy and uncertainty. However, if the patients are aware of the service, it can help them to reduce the perceived risk 
for engaging a healthcare service. Patients can obtain the information about the service credibility from a reference group or their personal experience. The credibility can help the patients to avoid collecting information for a long time and reduce their risk to experience the performance of the service. Service credibility is able to help the patients to reduce their cognitive effort. The availability of this piece of information in their mind allows them to start trusting their decision. In this sense, service credibility can affect the decision convenience and let the patients make the decision more easily and quickly. In this study, we proposed that service credibility can affect the patients' decision convenience.

H1. Service credibility positively affects patients' decision convenience.

\subsection{Relationship between service credibility and revisit intention}

In the research framework, service credibility is proposed to have a direct relationship with revisit intention. Service credibility can enhance the likelihood for the consumers to include that credible service in their consideration set for future purchase. Service credibility represents a piece of information about their performance to consumers. Information will include the quality of the goods or service, the worth of purchasing and the service. Consumers will rate that piece of information as the performance of the service providers. When the consumers have a positive impression toward the hospital, the consumers will trust the promises of the hospital and most likely will do the purchase or revisit. Service credibility can form a positive image in the consumers' mind and they will consider the service as trustworthiness and they will do the repurchase or revisit intention when they need the same service (Sehgal, 2014). With this statement, the researchers proposed that a patient who has confidence on the capability of the hospital to deliver its promises will be more willing to revisit the hospital.

H2. Service credibility positively affects the patients' revisit intention.

\subsection{Relationship between service credibility and affective commitment}

Service credibility is proposed as a relationship marketing tool that establishes the affective commitment of the patients. As a result, it can enhance the patients' decision making and revisit intention. Following Morgan and Hunt's (2012) studies, the centre of the relationship marketing theory is the relationship commitment and it is suggested that trust can be a driver leading to patients' affective commitment. When the patients have confidence in the service credibility of the hospital, they will believe that the organisation is trustworthiness for being able to deliver an excellent service (Erkmen \& Hancer, 2015). Patients will also have a higher affective commitment because of their trust in the organisation and this is an important evidence that proves their positive impression and trust towards the organisation's credibility (Erkmen \& Hancer, 2015). The expertise of the service provider that consists of good technical knowledge and ability to have a good competency, has been found to increase the affective commitment of the patients. This suggests that the service credibility can be a symbol of their expertise to deliver their promises. It will enhance the affective commitment of the patients towards a healthcare service. In this study, we propose that service credibility will affect the patient's affective commitment.

H3. Service credibility positively affects the patient's affective commitment.

\subsection{Relationship between of decision convenience and revisit intention}

Consistent with previous literature, the decision convenience is predicted to have a positive relationship with consumers' intention (Seiders, Voss, Godfrey, \& Grewal, 2007). Patients can make the decision easier if they have recognised their need for engaging the healthcare service. When the patients can make repurchase or revisit decision easily, it means that patients have developed trust and confidence in the healthcare service (Colwell, Aung, Kanetkar, \& Holden, 2008). Farquhar and Rowley (2009) argued that the decision convenience can increase the perception of a good quality service and can save their time and effort. Decision convenience can also be related to an uncertainty situation when patients are facing an uninformed decision making. The uncertainty situation occurs because patients are not aware of the service performance. Patients can reduce the sense of uncertainty or confusion when making a decision for a service through information searching. Patients will prefer to revisit the hospital that can let them have decision convenience. This is because the patients can easily think about the service of the hospital when a situation arises. Patients can become less worried about their decision. The study proposes that the decision convenience will affect patients' revisit intention positively.

H4. Decision convenience positively affects patients' revisit intention.

\subsection{Relationship between affective commitment and revisit intention}

Submit Date: 10.07.2018, Acceptance Date: 22.08.2018, DOI NO: 10.7456/1080SSE/176

Research Article - This article was checked by Turnitin

Copyright (C) The Turkish Online Journal of Design, Art and Communication 
In relating to the relationship marketing theory, it suggests that patients will feel connected to the organisation when they are affectively committed (Bolton et al., 2004). Patients will continue to do treatment or visit the hospital when they need the healthcare service. Some of the patients will like to maintain the relationship due to their preference and enjoy the relationship with the hospital (Verhoef, Franses, \& Hoekstra, 2002). A long-term relationship reflects patients' loyalty to the service and the hospital can have the opportunity to gain a better reputation, or probably to gain a higher revenue. This is evident in the studies of Iglesias, Singh and Batista-Foguet (2011) that consumers' emotional component within the affective commitment can be regarded as an important element that forges a good relationship between the consumers and the organisation. When the patients build a trust relationship, they will commit to the healthcare service and the service providers. Patients will continue to engage the service as they "stick" to the service provider. They will feel proud and comfortable when engaging the healthcare service. In this study, we propose that the affective commitment affects patients revisit intention.

H5. Affective commitment positively affects patients' revisit intention.

\subsection{Methodology}

The researchers employed survey approach to investigate patients' response on variables understudied. This study will adopt service credibility measures from Jeng (2016), affective commitment measures from Garbarino and Johnson (1999), decision convenience measures from Seiders et al. (2007) and revisit intention from Baek and King (2011). Outpatients will be the respondents from the southern region of Malaysia, namely Melaka and Johor. The researchers adhered to the suggestion of Hair, Black, Babin, and Anderson (2010) and adopted a sample size of 250 to minimise the non-normality effects and to leverage the statistical power that can be caused by small sample size. Melaka and Johor states are chosen as our sampling locations to align with the growing Southern Development Corridor as one of the economic growth corridors in Malaysia. AMOS Version 24 will be used to analysis the moment structures of the constructs understudied. Using this analysis, the researchers will examine the direct relationships among constructs graphically and investigate mediating roles of affective commitment and decision convenience simultaneously.

\subsection{Discussions and Implications}

\subsection{Expected Outcomes}

This study hypothesized the effects of the service credibility on patients' revisit intention. It is expected that the service credibility will contribute and affect patients' revisit intention by applying the relationship marketing theory. The service credibility can be used as a relationship marketing tool that influences patients' affective commitment. This insight is important for building a long-term relationship that can be a "winwin" situation for both patients and hospital management. The decision convenience and affective commitment which act as the mediators may add a finer level of practical implications and suggestions.

\subsection{Theoretical Implications}

This study focuses on the response of patients towards the service credibility for making the revisit decision. Service credibility can affect the decision convenience of the patients. Due to the increasing demand of having good healthcare service, patients require more time and more cognitive effort to evaluate different service providers and to make their decisions (Seiders et al., 2007). This study will further discuss the understanding of service convenience in the hospital sector. The decision convenience is proposed and it rarely has been discussed in the hospital setting.

Furthermore, the credibility of a service can enhance the bond between patients and a hospital. The relationship marketing theory is applied to discuss the affective commitment of patients with their revisit intention to the same hospital. Patients have emotionally tied with the hospital due to the trust in them towards the hospital. This can be caused by the service credibility of the hospital and can lead the patients' willingness to maintain a long-term relationship with the hospital. Their good experience will be a reference for them to consider the revisit intention in future.

Service credibility will have a direct impact on the patients' revisit intention. However, it is possible that this path can also be indirect to revisit intention through the patients' decision convenience and their affective commitment to the hospital. It indicates that the affective commitment of patients and their convenience to make the decision will be the important mediators that caused the patients to revisit the hospital in future.

\subsection{Managerial Implications}

Submit Date: 10.07.2018, Acceptance Date: 22.08.2018, DOI NO: 10.7456/1080SSE/176

Research Article - This article was checked by Turnitin

Copyright (C) The Turkish Online Journal of Design, Art and Communication 
The hospital should use suitable strategy to differentiate their services from others and to secure their position in the competitive market. The management of hospital need to recognize the service credibility as a critical role that will influence patients' revisit intention. The service credibility can generate the decision convenience and affective commitment for the patients and they are important to enhance their revisit intention. The management should refine their service credibility in the perception of patients. A good message about hospital should be presented to the patients. The message should be trustable and persuasive that can address the credibility of the hospital's service to patients.

In this study, the framework highlights the importance of service credibility to patients' revisit intention. This is needed to identify the possible alternative to managing the service credibility. It is obvious that the credibility can be enhanced by measuring patients' clear expression of the well-defined services (Erdem \& Swait, 1998). A good service can also project a good value to the hospital. The management of the hospital should understand their value proposition clearly and should implement it as an organization culture. The management should know the relationship between the value of the service and the hospital's value position. The credibility of a service can be enhanced by giving a good service to all patients and make them feel comfortable when they seek assistance from physicians and to have better medical decisions.

Service quality should always be maintained at a higher level so that patients will reduce their perceived risk towards the hospital. The patient satisfaction, their loyalty and trust can be used to gauge the quality of the service. The management should always evaluate their service offerings to the patients. In a hospital setting, it is important to forge a strong relationship with patients, build a strong positioning and stand out from other service providers.

\subsection{Conclusion}

This study provides significant insights into the influence of service credibility in a hospital setting. Taking into account of enhancing service credibility, service providers may arrive at the greatest mutual benefit to both patients and a successful market positioning. It will help the development of a hospital in future, and help getting more loyal consumers. Patients will have their own perception to judge the service credibility of a hospital when making a revisit decision. They can make a decision within a short time and trust their decision without doubts. The servicescape condition in a hospital can be another factor that does a further study about the patients' intention to visit a hospital (Lai, Chong, Ismail \& Tong, 2014; Lai, Chong, Ismail \& Tong, 2015). The servicescape evidence is needed to allow the patients give rating to the service standard of the hospital. Patients may feel pleasurable and satisfied when they personally experience the servicescape evidence that is made apparent by the hospital. It will be an added insight that contributes a further explanation to the credibility of a hospital that builds the trust of the patients.

\section{Acknowledgments}

We like to thank the Ministry of Higher Education, Malaysia for funding this research (Fundamental Research Grant Scheme - FRGS/1/2015/SS01/MMU/03/01). Heartfelt gratitude goes also to RMC of Multimedia University.

\section{References}

Ahmed, S. M. (2015). The Effects of Brand Credibility On Customers' Wom Communication: The Mediating Role Of Brand Commitment. Journal of Retailing and Consumer Services, 15(3), 164-176.

Berry, L. L., Seiders, K., \& Grewal, D. (2002). Understanding Service Convenience. Journal of Marketing, 66(3), $1-17$.

Bolton, R. N., Lemon, K. N., \& Verhoef, P. C. (2004). The Theoretical Underpinnings of Customer Asset Management: A Framework and Propositions for Future Research. Journal of the Academy of Marketing Science, 32(3), 271-292.

Chung, I.-K. C. I.-K., \& Lee, M.-M. L. M.-M. (2003). A study of influencing factors for repurchase intention in Internet shopping malls. Proceedings International Parallel and Distributed Processing Symposium, $0(C)$.

Colwell, S. R., Aung, M., Kanetkar, V., \& Holden, A. L. (2008). Toward a measure of service convenience: multiple-item scale development and empirical test. Journal of Services Marketing, 22(2), 160-169.

Crisnayanti, S. P. (2015). The Effect of Service Convenience towards Patient's Loyalty in Cendana Policlinic Dr. Soeradji Tirtonegoro General Hospital Klaten, 5(1), 18-22.

Erdem, L. I. N. (2014). Brand Credibility, Brand Consideration, and Choice, 31(1), 191-198.

Erkmen, E., \& Hancer, M. (2015). Linking brand commitment and brand citizenship behaviors of airline employees: "The role of trust." Journal of Air Transport Management, 42, 47-54.

Submit Date: 10.07.2018, Acceptance Date: 22.08.2018, DOI NO: 10.7456/1080SSE/176

Research Article - This article was checked by Turnitin

Copyright $\mathbb{C}$ The Turkish Online Journal of Design, Art and Communication 
Hair, J., C.Black, W., J.Babin, B., \& E.Anderson, R. (2010). Multivariate Data Analysis. Pearson.

Farquhar, J. D., \& Rowley, J. (2009). Convenience: a services perspective. Marketing Theory, 9(4), 425438.

Gundlach, G. T., Achrol, R. S., \& Mentzer, J. T. (1995). The Structure of Commitment in Exchange. Journal of Marketing, 59(1), 78-92.

Iglesias, O., Singh, J. J., \& Batista-Foguet, J. M. (2011). The role of brand experience and affective commitment in determining brand loyalty. Journal of Brand Management, 18(8), 570-582.

Jeng, S. P. (2016). The influences of airline brand credibility on consumer purchase intentions. Journal of Air Transport Management, 55, 1-8.

Kemp, E., \& Bui, M. (2011). Healthy brands: establishing brand credibility, commitment and connection among consumers. Journal of Consumer Marketing, 28(6), 429-437.

Koris, S. N. (2017). Malaysia on track to achieve RM1.15b medical tourism revenue this year. Retrieved from New Straits Time: https://www.nst.com.my/news/nation/2017/10/286552/malaysia-track-achieverm115b-medical-tourism-revenue-year-says-dr-hilmi

Lai, K. P., Chong, S. C., Ismail, H. B., \& Tong, D. Y. K. (2014). An explorative study of shopper-based salient e-servicescape attributes: A Means-End Chain approach. International Journal of Information Management, 34(4), 517-532.

Lai, K. P., Chong, S. C., Ismail, H. B., \& Tong, D. Y. K. (2015). Do salient e-servicescape attributes predict online brand image? International Journal of Internet Marketing and Advertising, 9(3), 209-232.

Macleod, A. (22 April, 2017). Special Report: Malaysia's healthcare sector provides a catalyst for growth. Retrieved from Global Risk Insights: http://globalriskinsights.com/2017/04/malaysia-healthcare-sector/

Morgan, R. M., \& Hunt, S. D. (2012). Theory of Relationship Marketing, 58(3), 20-38.

Palmatier, Robert W., Rajiv P. Dant, and Dhruv Grewal (2007), “A Comparative Longitudinal Analysis of Theoretical Perspectives of Interorganizational Relationship Performance," Journal of Marketing, 71 (October), 172-94.

Sehgal, P. J. K. (2014). Impact of service quality on customer satisfactionI, 34(3), 53-70. Retrieved from http://www.iosrjournals.org/iosr-jhss/papers/Vol18-issue5/F01853944.pdf

Seiders, K., Voss, G. B., Godfrey, A. L., \& Grewal, D. (2007). SERVCON: Development and validation of a multidimensional service convenience scale. Journal of the Academy of Marketing Science, 35(1), 144156.

Seyed Ghorban, Z., \& Tahernejad, H. (2012). A Study on Effect of Brand Credibility on Word of Mouth: With Reference to Internet Service Providers in Malaysia. International Journal of Marketing Studies, 4(1), $26-38$.

Solayappan, A., \& Jayakrishnan, J. (2010). Key Determinants of Brand-Customer Relationship in Hospital Industry. Petroleum-Gas University of Ploiesti Bulletin, LXII (4), 119-128.

Verhoef, P. C., Franses, P. H., \& Hoekstra, J. C. (2002). The Effect of Relational Constructs on Customer Referrals and Number of Services Purchased from a Multiservice Provider: Does Age of Relationship Matter? Journal of the Academy of Marketing Science, 30(3), 202-216.

Wang, X., \& Yang, Z. (2010). The Effect of Brand Credibility on Consumers' Brand Purchase Intention in Emerging Economies: The Moderating Role of Brand Awareness and Brand Image. Journal of Global Marketing, 23(3), 177-188. 